\title{
Influences of Growth Velocity and Fe Content on Microstructure, Microhardness and Tensile Properties of Directionally Solidified Al-1.9Mn-xFe Ternary Alloys
}

\author{
Emin Çadırlı ${ }^{a}$, Aynur Aker ${ }^{b}$, Yusuf Kaygısız ${ }^{c}$, Mevlüt Şahin ${ }^{d}$ \\ ${ }^{a}$ Department of Physics, Faculty of Arts and Sciences, Ömer Halisdemir University, Niğde, Turkey \\ ${ }^{b}$ Department of Computer Instructional Technologies, Faculty of Education, Siirt University, Siirt, Turkey \\ ${ }^{c}$ Ereğli Faculty of Engineering and Natural Sciences, Necmettin Erbakan University, Konya, Turkey \\ ${ }^{d}$ Technical Vocational School of Sciences, Ömer Halisdemir University, Niğde, Turkey
}

Received: January 17, 2017; Revised: March 15, 2017; Accepted: April 9, 2017

\begin{abstract}
In this study, influences of growth velocity and composition (Fe content) on the microstructure (rod spacing) and mechanical properties (microhardness, ultimate tensile strength and fracture surface) of Al-Mn-Fe ternary alloys have been investigated. $\mathrm{Al}-1.9 \mathrm{Mn}-\mathrm{xFe}(\mathrm{x}=0.5,1.5$ and $5 \mathrm{wt}$. \%) were prepared using metals of $99.99 \%$ high purity in the vacuum atmosphere. At a constant temperature gradient $(6.7 \mathrm{~K} / \mathrm{mm})$, these alloys were directionally solidified upwards under various growth velocities $(8.3-978 \mu \mathrm{m} / \mathrm{s})$ using a Bridgman-type directional solidification furnace. The results show that two kinds of Al-rich $\alpha$ - $\mathrm{Al}$ phase and $\mathrm{Fe}$-rich intermetallic $\left(\mathrm{Al}_{6} \mathrm{FeMn}\right)$ phase may be present in the final microstructures of the alloys when the Fe content increases from $0.5 \mathrm{wt} . \%$ to $5 \mathrm{wt} . \%$. $\mathrm{Al}_{6} \mathrm{FeMn}$ intermetallic rod spacing, microhardness and ultimate tensile strength were measured and expressed as functions of growth velocity and $\mathrm{Fe}$ content by using a linear regression analysis method. According to experimental results, the microhardness and ultimate tensile strength of the solidified samples increase with increase in the growth velocity and $\mathrm{Fe}$ content and decrease in rod spacing. The elongations of the alloys decrease gradually with increasing growth velocity and $\mathrm{Fe}$ content.
\end{abstract}

Keywords: Al alloys, intermetallics, directional solidification, microhardness, tensile strength, fracture surface

\section{Introduction}

Among the alloys of the Al-Mn system, also known as the $3 \mathrm{XXX}$ alloys series, the most widely used is the 3003 alloy'. Owing to their good conformability, corrosion resistance, weldability, and allied reasonable mechanical resistance, they are becoming very interesting materials. They are commonly used in the shape of plates and sheets, and can also be extruded or forged, although their use in this form has been limited. Some examples of final applications are food packing (e.g., cans and domestic utensils), tiles, and heat exchangers ${ }^{1}$. One great advantage of these alloys is attributed to their composition variation and the presence of solute in solid solution. Although their optimum composition has relatively narrow limits, small variations do not substantially affect their manufacture or properties.

In the binary Al-Mn alloy system, the maximum solubility of manganese in the $\alpha$-solid solution is $1.82 \mathrm{wt} \%$ at the eutectic temperature of $658.5^{\circ} \mathrm{C}$, the solubility decreasing with decreasing temperature ${ }^{1-4}$. Alloys in this group, Al-Mn, and $\mathrm{Al}-\mathrm{Mn}-\mathrm{Mg}$, are generally not age-hardenable. These alloys tend to be used when moderate strength combined with high ductility, good weldability, good formability, and excellent corrosion resistance are required. Commercial AlMn alloys generally contain $0.25-1.25$ wt. $\%$ manganese ${ }^{1,4,5}$.

*e-mail: ecadirli@gmail.com
In these alloys, $\mathrm{Fe}$ and $\mathrm{Si}$ are normally present as impurities, and sometimes $\mathrm{Cu}, \mathrm{Mg}$ and $\mathrm{Zn}$ are also added as minor alloying elements ${ }^{1,3,4}$. There are three primary phases in the $\mathrm{Al}-\mathrm{Fe}-\mathrm{Mn}$ system; $\mathrm{Al}, \mathrm{Al}_{3} \mathrm{Fe}$, and $\mathrm{Al}_{6}(\mathrm{MnFe})^{1,6}$. The maximum solubility of iron in aluminium is $0.03-0.04 \mathrm{wt} . \%$, and this is unchanged in the ternary alloys. On the other hand, the manganese solubility is decreased. The maximum solubility of manganese in iron-bearing alloys may be approximately one half of that in the binary aluminium-manganese alloys ${ }^{1}$. The binary diagrams have limited application because commercial aluminium alloys always contain appreciable amounts of iron, which significantly affect the microstructure. Because of a greater tendency of the $\mathrm{Fe}$ atoms to segregate, the intermetallics formed during solidification contain relatively more $\mathrm{Fe}$ than $\mathrm{Mn}$. Al-Mn-Fe and Al-Mn-Fe-Si alloys are important commercial aluminium alloys. They have been used in many industrial sectors and in particular in the rapidly growing aluminium heat exchanger market. The previous works mainly revealed the influences of the $\mathrm{Mn}$ and $\mathrm{Fe}$ content on the type and size of different Al-Mn and Al-Mn-Si alloys ${ }^{7-9}$ or the cooling rate on the evolution of different $\mathrm{Al}-\mathrm{Mn}$ and $\mathrm{Al}-\mathrm{Mn}-\mathrm{Si}$ alloys during the solidification process $^{10,11}$ separately. Still very limited work has reported systematically about the influences of the Fe content, the $\mathrm{Fe} / \mathrm{Mn}$ ratio and cooling rate on the modification of Al-Mn and Al-Mn-Si alloys. 
The aim of the present work is to experimentally investigate effects of growth velocity $(V)$ and Fe content $\left(C_{o}\right)$ on the microstructure (rod spacing, $\lambda$ ), microhardness $(H V)$ and ultimate tensile strength $\left(\sigma_{u}\right)$ of the directionally solidified Al-1.9Mn-xFe alloys ( $\mathrm{x}=0.5,1.5$ and 5 wt. \%) under well-controlled experimental conditions.

\section{Experimental Procedure}

\subsection{Sample preparation and directional solidification}

Using the vacuum melting and hot filling furnaces ${ }^{12,13}$, Al-1.9Mn-xFe alloys ( $x=0.5,1.5$ and 5 wt. $\%)$ alloys have been prepared under vacuum atmosphere by using $99.99 \%$ purity metals taking into account the phase diagram as shown Fig. $1^{14}$. After allowing time for melt homogenization, the molten alloy was poured into graphite crucibles $(20 \mathrm{~cm}$ in length $0.4 \mathrm{~cm}$ inner diameter and $0.64 \mathrm{~cm}$ outer diameter) held in a specially constructed casting furnace (Hot Filling Furnace) at approximately $50 \mathrm{~K}$ above the melting point of alloy. The molten alloy was directionally solidified from bottom to top to ensure that the crucible was completely full.

Then, each sample was positioned in a Bridgman-type furnace in a graphite cylinder (Fig. 2). The block diagram of the experimental design and details of the Bridgman-type directional solidification furnace are given in previous studies $^{12,13}$. In the experimental technique, the sample was heated about $100 \mathrm{~K}$ above the melting temperature and solidification of the samples was carried out at a constant temperature gradient, $G(6.7 \mathrm{~K} / \mathrm{mm})$ under various growth velocities $(8.3-978 \mu \mathrm{m} / \mathrm{s})$ in a Bridgman-type directional solidification furnace. After $10 \mathrm{~cm}$ steady state growth, the samples were quenched by rapidly pulling it down into the water reservoir. The temperature of water in the reservoir was kept at $275 \mathrm{~K}$ with accuracy of $\pm 0.1 \mathrm{~K}$ by using a digital heating / refrigerating circulating bath (Poly Science-9102 model) to obtain a well quenched solid-liquid interface in the present work. The sample temperature was also controlled to accuracy of $\pm 0.1 \mathrm{~K}$ using a temperature controller (Eurotherm-2604 model). In order to see the effects of the growth velocity and Fe content on the $\lambda, H V$ and $\sigma u$, directional solidification experiments were repeated for each compositions of $\mathrm{Al}-1.9 \mathrm{Mn}-\mathrm{xFe}$ alloy $(\mathrm{x}=0.5,1.5$ and 5 wt. \%).

\subsection{Measurement of temperature gradient and growth velocity}

The temperatures in the sample were measured by three K-type $0.5 \mathrm{~mm}$ in diameter insulated thermocouples which were fixed within the sample with spacing of $5 \mathrm{~mm}$. In this study, A tapered thin alumina tube (120 mm length, $1.9 \mathrm{~mm}$ OD $\times 1.2 \mathrm{~mm}$ ID) was used to insulate the thermocouples from the melt. All the thermocouple's ends were then connected the measurement unit consists of data-logger (Pico TC-08 model) and computer. The cooling rates were recorded with a data-logger via computer during solidification process. When the solid/liquid interface was at the second thermocouple, the temperature difference between the first and second thermocouples $(\Delta \mathrm{T})$ was read from data-logger record. The temperature gradient $(\mathrm{G}=\Delta \mathrm{T} / \Delta \mathrm{X})$ in the liquid phase for each sample was determined by using the measured value of $\Delta \mathrm{T}$ and $\Delta \mathrm{X}$.

The growth velocity $(V)$ was calculated with two different methods. In the first method, the values of growth velocity

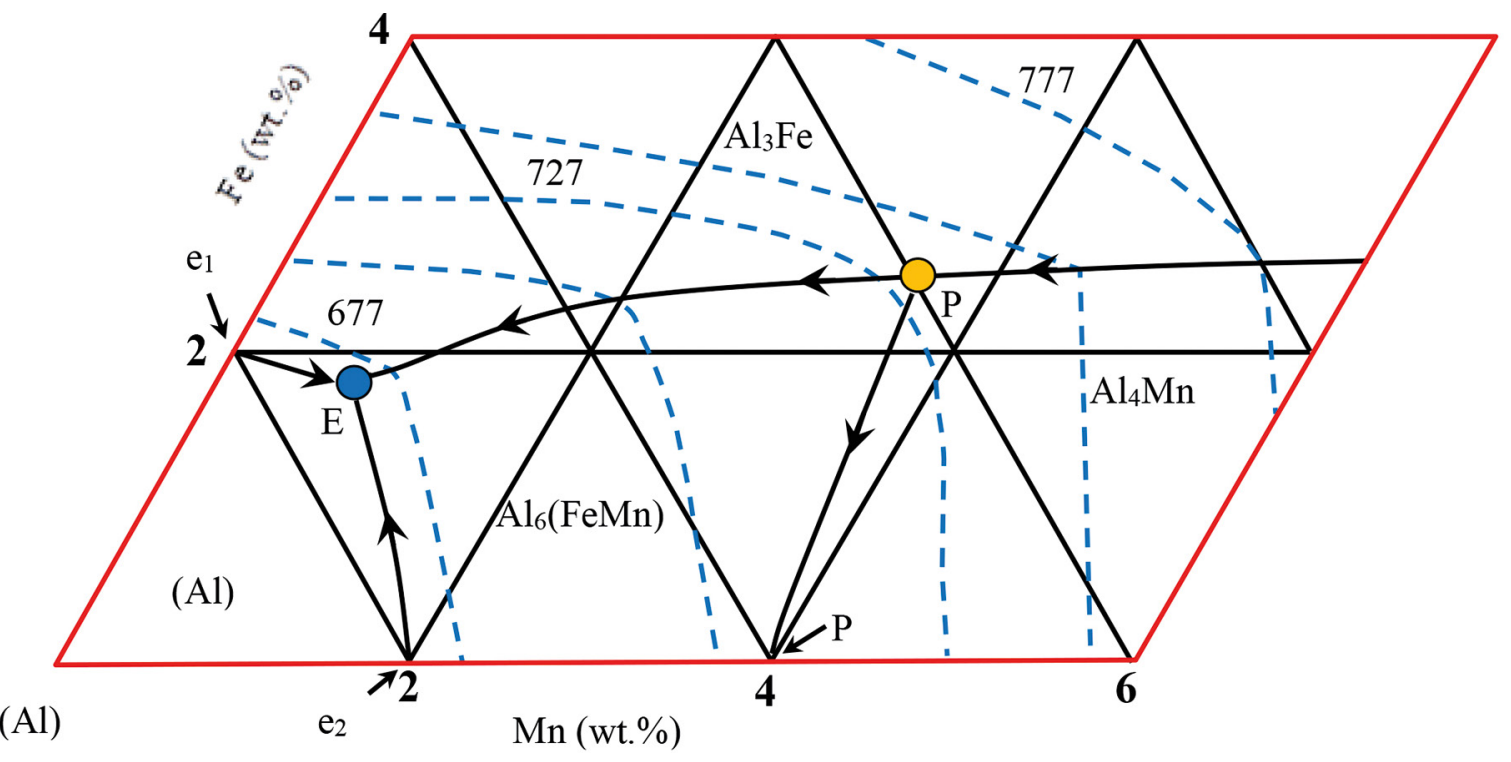

Fig. 1. Al-rich corner of the ternary Al-Mn-Fe phase diagram adopted from ref. ${ }^{14}$ 


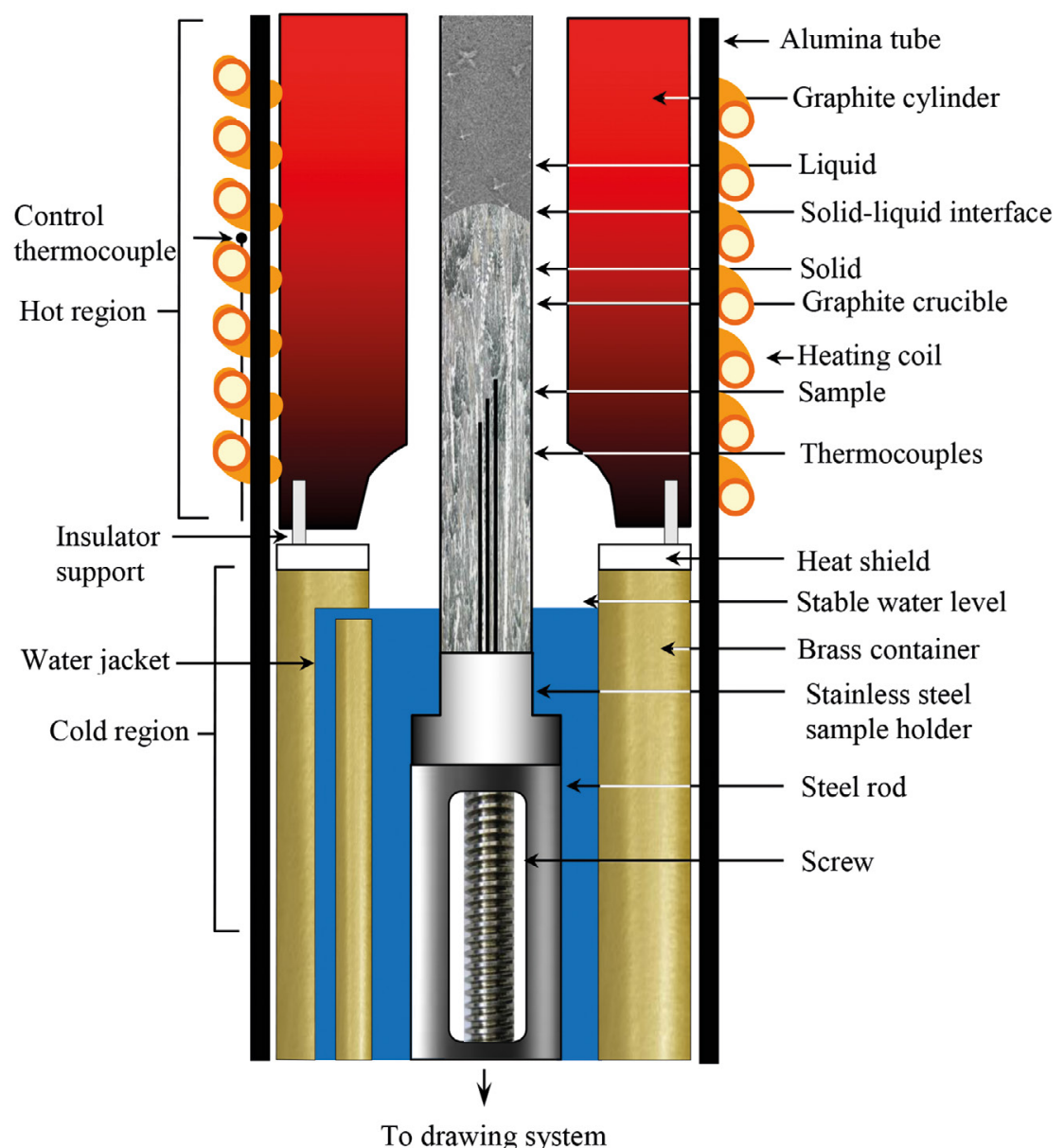

Fig. 2. The Bridgman-type directional solidification furnace

were calculated from the measurements of the time taken for the solid-liquid interface to pass the thermocouples separated by a known distance. In the second method, the total solidification time and solidification distance (on the longitudinal section of the polished sample) were measured. The ratios of the distances to the times were measured to obtain the growth velocities and these were similar for both methods.

\subsection{Metallographic analysis}

Precise metallographic processes were used to prepare the samples for microstructural analysis.

The quenched sample was removed from the graphite crucible and $1 \mathrm{~cm}$ in lengths from the top and bottom were cropped off and discarded. The rest of the sample was ground, polished and etched to reveal the quenched interface. Then, the longitudinal and transverse sections of sample were mounted in a cold-setting epoxy-resin. The longitudinal and transverse sections were wet ground down to grit 4000 and mechanically polished using $6,3,1$ and $1 / 4 \mathrm{~mm}$ diamond paste (ASTM Standard E3). After the polishing process, the microstructure was revealed by chemical etching process ( $10 \mathrm{~mL}$ sulfuric, $5 \mathrm{~mL}$ hydrofluoric acid and $85 \mathrm{~mL} \mathrm{H}_{2} \mathrm{O}$ for a 15 seconds at room temperature). The micrographs of the samples were taken with an optical microscope (Nikon Eclipse MA 100 inverted model) using different objectives. Eutectic rod spacings $(\lambda)$ were measured with the Adobe Photoshop CS3 program, with the magnification factor taken into account.

\subsection{Identification of solid phases and measurement of eutectic spacings}

Scanning electron microscopy with energy dispersive $\mathrm{X}$-ray spectroscopy (SEM/EDX) is the best known and most widely-used of the surface analytical techniques. EDX analysis was performed to determine the composition of the phases in the Al-Mn-Fe alloys at $20 \mathrm{keV}$ using the X-ray lines (LEO 440 model). The EDX and XRD analysis results are given in detail in section 3.1. Different methods ${ }^{15-17}$ have been used to measure of eutectic spacings on the microstructure. As can be seen from Fig. 3, the rod or plate-like spacings were measured with a linear intersection method $^{15}$ on the 

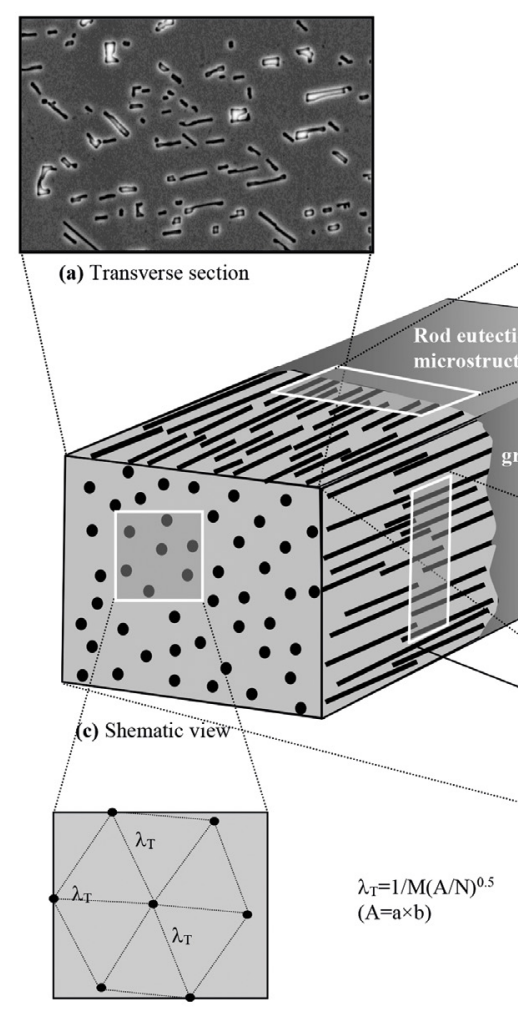

(e) Triangle method

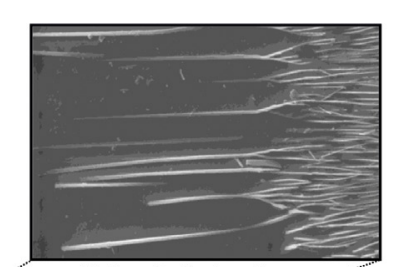

(b) Longitudinal section $+2$

Fig. 3. The shematic illustration of rod spacings measurements from the longitudinal and transverse Sections

longitudinal section. Two different methods were used to measure the rod spacings on the transverse sections. The first method is the triangle method ${ }^{16}$. The triangle is formed by joining the three neighbouring rod centers, and each sides of the triangle corresponded to $\lambda$. The second method is the area counting method ${ }^{17}$. The rod spacings measured on the transverse section, $\lambda_{T}$, gave more accurate results than the rod spacings measured on the longitudinal section, $\lambda_{L}$. There might be two reasons for this: firstly, at least five times more rod spacing can be measured from the transverse section than the longitudinal section; secondly, $\lambda_{T}$ is perpendicular to the growth direction whereas $\lambda_{L}$ is parallel to the growth direction and it depends on the polished plane. The measurements on the transverse section were preferred rather than the longitudinal section because of these reasons. As a result, the values of $\lambda_{T}$ measured on the transverse section are more reliable than the values of $\lambda_{L}$ measured on the longitudinal section.

\subsection{Measurement of microhardness and tensile strength}

The purpose of this investigation was to obtain the relationships between solidification parameters ( $V$ and $C_{o}$ ) and mechanical properties ( $H V$ and $\sigma_{u}$ ) of the studied alloys. Microhardness measurements (all specimens were tested according to ASTM E384) in this work were made with a Future-Tech FM-700 model hardness measuring test device $^{18}$ using a $300 \mathrm{~g}$ load and a dwell time of 10 seconds giving a typical indentation depth about $30-60 \mathrm{~mm}$. The microhardness values were measured from on the transverse sections of samples. The minimum impression spacing (center to edge of adjacent impression) was about 3 times the diagonal and was located at least $0.5 \mathrm{~mm}$ from the edge of sample. To ensure cleanliness the surfaces of the samples were polished prior to $H V$ measurement. Each reading was an average of at least ten separate measurements taken randomly on the surface of the samples. The highest and the lowest values of the ten reading were disregarded. Some errors are inevitable during microhardness measurements. These errors are due to factors such as surface quality, inhomogeneities in the microstructure and ambiguity of indenter traces. The estimated error in the microhardness measurements with statistical data analysis is about $5 \%$.

The measurements of the tensile strength were made at room temperature with a Shimadzu AG-IS universal testing machine (all specimens were tested according to ASTM E4). Round rod tensile samples with a diameter of $4 \mathrm{~mm}$ and gauge length of $40 \mathrm{~mm}$ were prepared from directionally solidified rod samples with different composition. The tensile axis was chosen parallel to the growth direction of the sample. The tensile tests were repeated three times and the average value was taken. It has been found that a standard deviation was approximately $5 \%$. 


\section{Results and Discussion}

In order to observe the effect of growth velocity and Fe content on microstructure and mechanical properties of Al-1.9Mn-xFe alloys, eutectic rod spacings, microhardness and tensile strength of alloys were measured with increasing growth velocity and Fe content.

\subsection{Microstructure characterization}

According to EDX results as shown in Fig. 4 and the quantity of components in each phases, dark rod eutectic phase (white rectangular frames) and quenched liquid phase (red rectangular frames) were identified as $\mathrm{Al}_{6} \mathrm{FeMn}$ intermetallic phase (rod-or plate-like particles) and Al-rich $\alpha$-Al phase respectively. The compositions of $\alpha$-Al phases are close to nominal compositions. The constituent phases of the samples were identified by X-ray diffraction (XRD) analysis using a Siemens X-ray diffractometer (Model D500) with $\mathrm{Cu} \mathrm{K} \alpha\left(\mathrm{k}=1.79 \mathrm{~A}^{\circ}\right)$ radiation at room temperature. Sample was cut from the ingots and polished to a mirror finish. Measurements were performed by step scanning $2 \mathrm{~h}$ from $20^{\circ}$ to $65^{\circ}$ with a $0.02^{\circ}$ step size. A count time of $1 \mathrm{~s}$ per step was used, giving a total scan time of $\sim 1.5 \mathrm{~h}$. Figure 5 shows peaks obtained in the analysis compared with the JCPDS data and $\alpha$-Al phase (red squares) and $\mathrm{Al}_{6}$ FeMn (black circles) intermetallic phases have been detected. Dominant phases in the microstructure were $\alpha-\mathrm{Al}$ and $\mathrm{Al}_{6} \mathrm{FeMn}$ phases. All these phases were also confirmed in the corresponding microstructure (Fig. 4). Both EDX analysis (Fig. 4) and XRD pattern (Fig. 5) strongly indicate that only two phases ( $\alpha$-Al and $\mathrm{Al}_{6} \mathrm{FeMn}$ ) are present in microstructure of the cast sample.

Figure 6 shows the microstructures of the studied alloys with Fe content varying from $0.5 \mathrm{wt} . \%$ to $5 \mathrm{wt} . \%$ in the range of $\mathrm{V}(8.3-978 \mu \mathrm{m} / \mathrm{s})$. Microstructures of the studied alloys consist of $\alpha-\mathrm{Al}$ and $\mathrm{Al}_{6} \mathrm{FeMn}$ intermetallic (rod eutectic
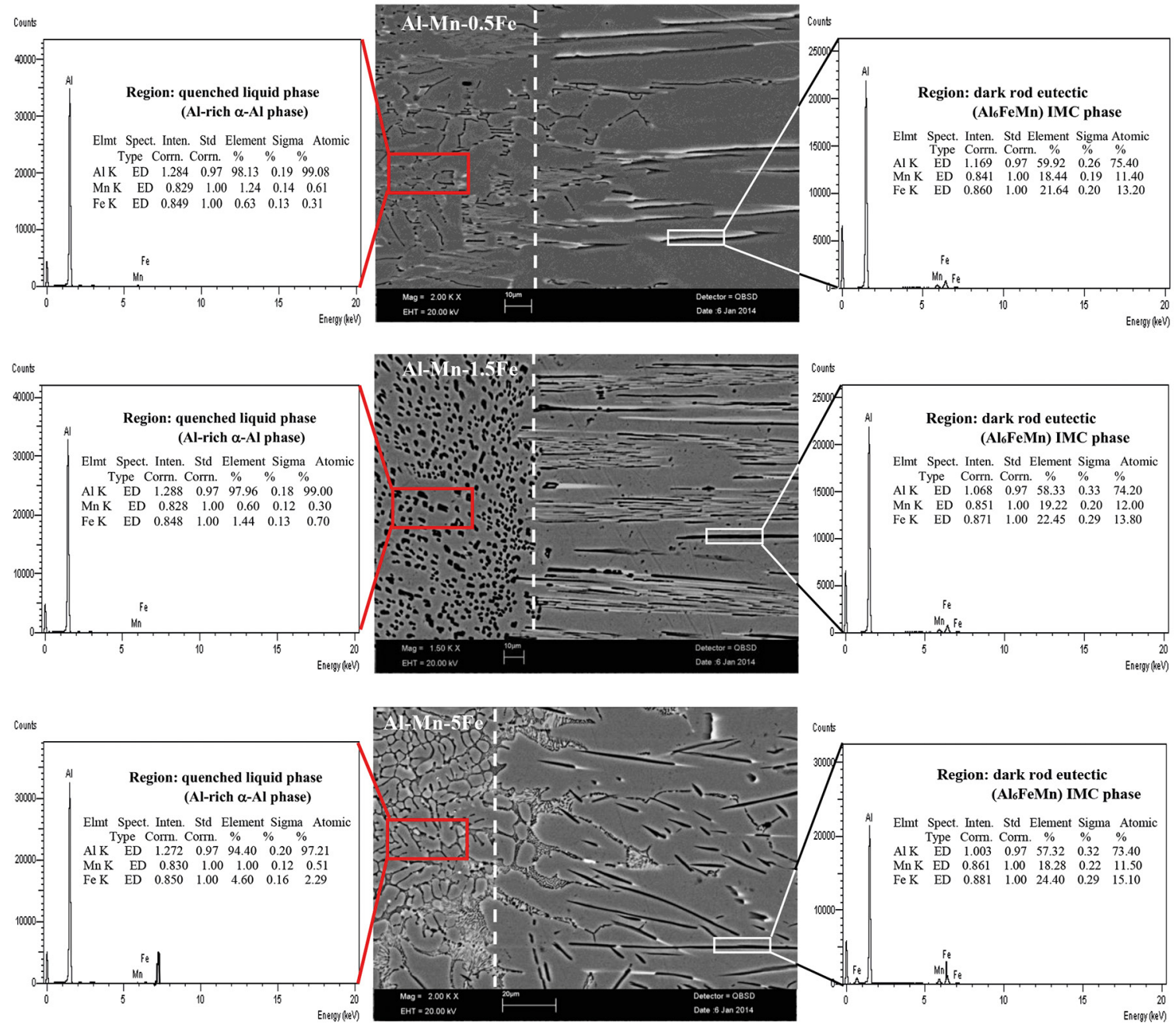

Figure 4. The chemical composition analysis of $\mathrm{Al}-1.9 \mathrm{Mn}-\mathrm{xFe}$ ternary alloys by using SEM-EDX, dark rod eutectic phase (A16MnFe intermetallics) and quenched liquid phase (Al-rich $\alpha$-Al phase) 


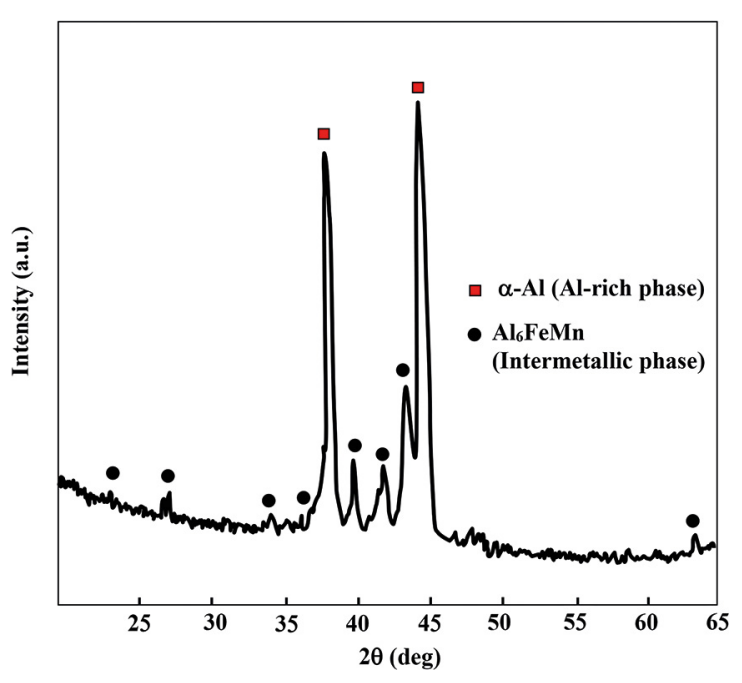

Fig. 5 X-ray diffraction patterns obtained from the $\mathrm{Al}-1.9 \mathrm{Mn}-5 \mathrm{Fe}$ ternary alloy
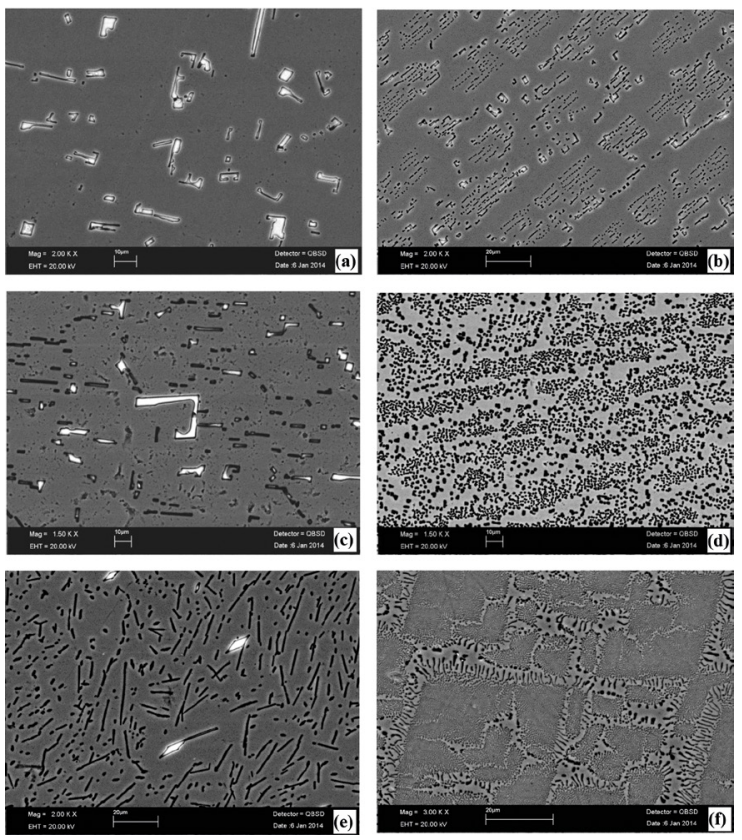

Fig. 6 Rod eutectic microstructures images of directionally solidified Al-1.9Mn-xFe alloys at constant $\mathrm{G}(6.7 \mathrm{~K} / \mathrm{mm})$ (a) Al-1.9Mn-0.5Fe $(V=8.3 \mu \mathrm{m} / \mathrm{s})$ (b) Al-1.9Mn-0.5Fe ( $V=987 \mu \mathrm{m} / \mathrm{s})$ (c) Al-1.9Mn-1.5Fe $(V=8.3 \mu \mathrm{m} / \mathrm{s})(\mathrm{d}) \mathrm{Al}-1.9 \mathrm{Mn}-1.5 \mathrm{Fe}(V=978 \mu \mathrm{m} / \mathrm{s})(\mathrm{e}) \mathrm{Al}-1.9 \mathrm{Mn}-5 \mathrm{Fe}$ $(V=8.3 \mu \mathrm{m} / \mathrm{s})$ (b) Al-1.9Mn-5Fe $(V=978 \mu \mathrm{m} / \mathrm{s})$

and plate-like structure) phase. In the case of irregular eutectic structures (plate-like), the minimum and maximum eutectic spacings were measured both longitudinal section (linear intersection method) and transverse section (triangle method and area counting method) of samples. Numerous measurements were taken to improve statistical confidence and the average of these values was used. Increasing the content of $\mathrm{Fe}$ and growth velocity, grain size of eutectics $\left(\mathrm{Al}_{6} \mathrm{FeMn}\right.$ intermetallics) reduced and microstructure highly refined (Fig. 6e-f).

\subsection{Effect of growth velocity and composition (Fe content) on the eutectic rod spacings}

As mentioned above, $\mathrm{Al}-1.9 \mathrm{Mn}-\mathrm{xFe}$ alloys were also solidified with a constant $G(6.7 \mathrm{~K} / \mathrm{mm})$ in a wide range of $V(8.3-978 \mathrm{~mm} / \mathrm{s})$. As can be seen from Fig. 6, rod eutectic microstructures were observed at different $V$ and $C_{o}$ values for Al-1.9Mn-xFe alloys. At the low values of $V(8.3 \mu \mathrm{m} / \mathrm{s})$ and $C_{o}(0.5 \mathrm{wt} . \% \mathrm{Fe})$ the microstructure consists of mainly coarse rod and plate-like eutectics. At the high values of $V$ $(978 \mu \mathrm{m} / \mathrm{s})$ and $C_{o}(5 \mathrm{wt} . \% \mathrm{Fe})$, it is seen that increase in the $V$ and $C_{o}$ leads to a refined eutectic microstructure. So that, the coarse rod and plate-like eutectic change into fine rod eutectic. Variations in $\lambda$ with $V$ at the constant $G$ for different Al-1.9Mn-xFe alloys are shown in Fig. 7a. The variation of $\lambda$ versus $V$ plot is essentially linear for the growth velocities between 8.3 and $978 \mu \mathrm{m} / \mathrm{s}$. It can be seen that the points fall on a family of straight lines each corresponding to a $C_{o}$. A linear regression analysis gives the proportionality equation as $\lambda=\mathrm{k} V^{-\mathrm{a}}$. Fig. 7 a shows clearly that an increase in $V$ produce a decrease in $\lambda$. The values of the growth velocity exponent are equal to $0.39,0.33$ and 0.34 for the $\mathrm{Al}-1.9 \mathrm{Mn}-\mathrm{xFe}(\mathrm{x}=0.5$, 1.5 and 5) alloys respectively (see Table 1).

As expected, the formations of the microstructures varied with the alloy Fe content at a constant $G(6.7 \mathrm{~K} / \mathrm{mm})$. As the value of Fe content $\left(C_{o}\right)$ was increased, the rod spacings $(\lambda)$
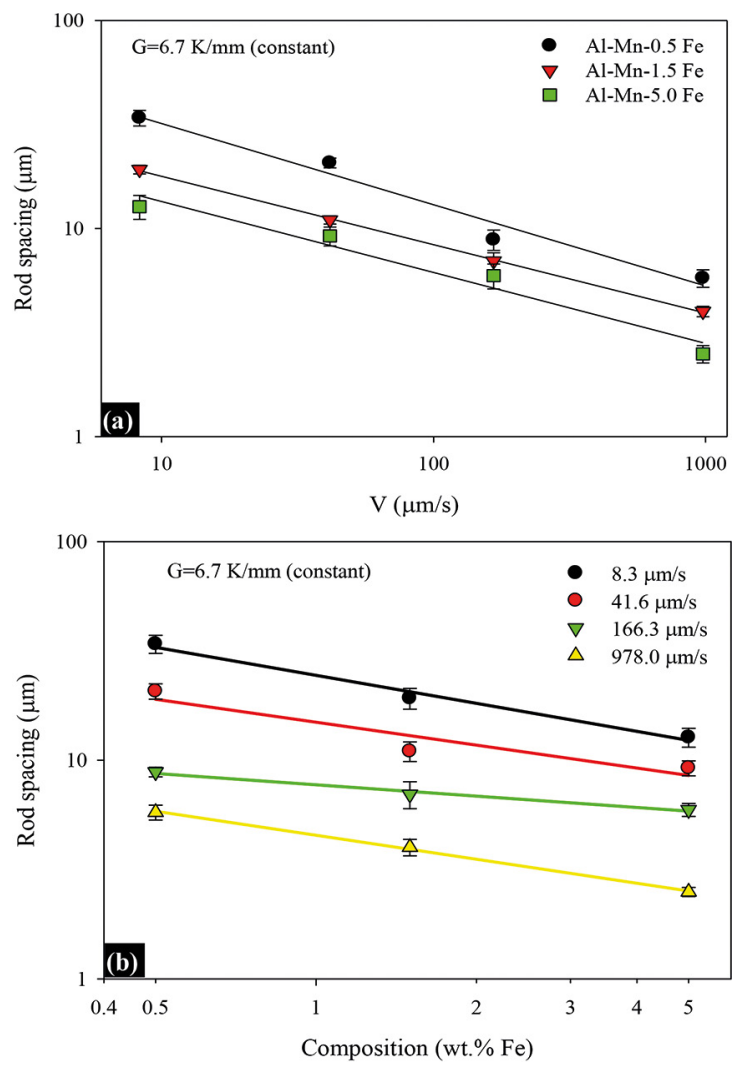

Fig. 7 (a)Variation of $\lambda$ versus $V$ for different Fe contents (b)Variation of $\lambda$ versus $\mathrm{C}_{\mathrm{o}}$ for different $V$ 
Table 1. The relationships among $\mathrm{V}, \mathrm{HV}, \sigma_{\mathrm{U}}, \mathrm{C}_{\mathrm{o}}$, and $\lambda$ for $\mathrm{Al}-1.9 \mathrm{Mn}-\mathrm{xFe}$ alloys

\begin{tabular}{|c|c|c|c|}
\hline Composition & Relationships & Constants (k) & Correlation coefficients (r) \\
\hline \multirow{4}{*}{$\begin{array}{l}\text { Al-Mn- } 0.5 \mathrm{Fe} \\
\text { (constant) }\end{array}$} & $\lambda=\mathrm{k}_{1} \mathrm{~V}^{-0.39}$ & $\mathrm{k}_{1}=77\left(\mu \mathrm{m}^{1.39} \mathrm{~s}^{-0.39}\right)$ & $r_{1}=-0.984$ \\
\hline & $\mathrm{HV}=\mathrm{k}_{2} \lambda^{-0.11}$ & $\mathrm{k}_{2}=20\left(\mathrm{~kg} \mathrm{~mm}^{-1.89}\right)$ & $r_{2}=-0.985$ \\
\hline & $\mathrm{HV}=\mathrm{k}_{3} \mathrm{~V}^{0.04}$ & $\mathrm{k}_{3}=34\left(\mathrm{~kg} \mathrm{~mm}^{-2.04} \mathrm{~s}^{0.04}\right)$ & $r_{3}=0.993$ \\
\hline & $\sigma=\mathrm{k}_{4} \mathrm{~V}^{0.06}$ & $\mathrm{k}_{4}=151\left(\mathrm{MPa} \mathrm{mm}^{-0.06} \mathrm{~s}^{0.06}\right)$ & $\mathrm{r}_{4}=0.988$ \\
\hline \multirow[t]{4}{*}{ Al-Mn-1.5Fe (constant) } & $\lambda=\mathrm{k}_{5} \mathrm{~V}^{-0.33}$ & $\mathrm{k}_{5}=38\left(\mu \mathrm{m}^{1.33} \mathrm{~s}^{-0.33}\right)$ & $r_{5}=-0.999$ \\
\hline & $\mathrm{HV}=\mathrm{k}_{6} \lambda^{-0.12}$ & $\mathrm{k}_{6}=22\left(\mathrm{~kg} \mathrm{~mm}^{-1.88}\right)$ & $r_{6}=-0.975$ \\
\hline & $\mathrm{HV}=\mathrm{k}_{7} \mathrm{~V}^{0.04}$ & $\mathrm{k}_{7}=43\left(\mathrm{~kg} \mathrm{~mm}^{-2.04} \mathrm{~s}^{0.04}\right)$ & $r_{7}=0.974$ \\
\hline & $\sigma=\mathrm{k}_{8} \mathrm{~V}^{0.04}$ & $\mathrm{k}_{8}=181\left(\mathrm{MPa} \mathrm{mm}{ }^{-0.04} \mathrm{~s}^{0.04}\right)$ & $r_{8}=0.993$ \\
\hline \multirow{4}{*}{$\begin{array}{l}\text { Al-Mn-5Fe } \\
\text { (constant) }\end{array}$} & $\lambda=\mathrm{k}_{9} \mathrm{~V}^{-0.34}$ & $\mathrm{~K}_{9}=30\left(\mu \mathrm{m}^{1.34} \mathrm{~s}^{-0.34}\right)$ & $r_{9}=-0.979$ \\
\hline & $\mathrm{HV}=\mathrm{k}_{10} \lambda^{-0.15}$ & $\mathrm{k}_{10}=24\left(\mathrm{~kg} \mathrm{~mm}^{-1.85}\right)$ & $r_{10}=-0.998$ \\
\hline & $\mathrm{HV}=\mathrm{k}_{11} \mathrm{~V}^{0.05}$ & $\mathrm{k}_{11}=60\left(\mathrm{~kg} \mathrm{~mm}^{-2.05} \mathrm{~s}^{0.05}\right)$ & $\mathrm{r}_{11}=0.983$ \\
\hline & $\sigma=\mathrm{k}_{12} \mathrm{~V}^{0.05}$ & $\mathrm{k}_{12}=194\left(\mathrm{MPa} \mathrm{mm}^{-0.05} \mathrm{~s}^{0.05}\right)$ & $r_{12}=0.993$ \\
\hline Growth velocity $(\mu \mathrm{m} / \mathrm{s})$ & Relationships & Constants (k) & Correlation coefficients $(r)$ \\
\hline \multirow[t]{3}{*}{8.3 (constant) } & $\lambda=\mathrm{k}_{13} \mathrm{Co}^{-0.43}$ & $\mathrm{k}_{13}=0.024 \mathrm{~mm}(\mathrm{wt} . \% \mathrm{Fe})^{0.43}$ & $r_{13}=-0.992$ \\
\hline & $\mathrm{HV}=\mathrm{k}_{14} \mathrm{Co}^{0.23}$ & $\mathrm{k}_{14}=33 \mathrm{kgmm}^{-2}(\mathrm{wt} . \% \mathrm{Fe})^{-0.23}$ & $\mathrm{r}_{14}=0.999$ \\
\hline & $\sigma=\mathrm{k}_{15} \mathrm{Co}^{0.12}$ & $\mathrm{k}_{15}=131 \mathrm{MPa}(\text { wt. } \% \mathrm{Fe})^{-0.12}$ & $\mathrm{r}_{15}=0.934$ \\
\hline \multirow[t]{3}{*}{41.6 (constant) } & $\lambda=\mathrm{k}_{16} \mathrm{Co}^{-0.35}$ & $\mathrm{k}_{16}=0.015 \mathrm{~mm}(\mathrm{wt} . \% \mathrm{Fe})^{0.35}$ & $r_{16}=-0.942$ \\
\hline & $\mathrm{HV}=\mathrm{k}_{17} \mathrm{Co}^{0.23}$ & $\mathrm{k}_{17}=35 \mathrm{kgmm}^{-2}(\mathrm{wt} . \% \mathrm{Fe})^{-0.23}$ & $\mathrm{r}_{17}=0.997$ \\
\hline & $\sigma=\mathrm{k}_{18} \mathrm{Co}^{0.12}$ & $\mathrm{k}_{18}=140 \mathrm{MPa}(\mathrm{wt} . \% \mathrm{Fe})^{-0.12}$ & $\mathrm{r}_{18}=0.908$ \\
\hline \multirow[t]{3}{*}{166.3 (constant) } & $\lambda=\mathrm{k}_{19} \mathrm{Co}^{-0.17}$ & $\mathrm{k}_{19}=0.007 \mathrm{~mm}(\mathrm{wt} . \% \mathrm{Fe})^{0.17}$ & $r_{19}=-0.991$ \\
\hline & $\mathrm{HV}=\mathrm{k}_{20} \mathrm{Co}^{0.24}$ & $\mathrm{k}_{20}=37 \mathrm{kgmm}^{-2}(\mathrm{wt} . \% \mathrm{Fe})^{-0.24}$ & $\mathrm{r}_{20}=0.998$ \\
\hline & $\sigma=\mathrm{k}_{21} \mathrm{Co}^{0.12}$ & $\mathrm{k}_{21}=152 \mathrm{MPa}(\mathrm{wt} . \% \mathrm{Fe})^{-0.12}$ & $r_{21}=0.942$ \\
\hline \multirow[t]{3}{*}{978.0 (constant) } & $\lambda=\mathrm{k}_{22} \mathrm{Co}^{-0.37}$ & $\mathrm{k}_{22}=0.005 \mathrm{~mm}(\mathrm{wt} . \% \mathrm{Fe})^{0.37}$ & $r_{22}=-0.998$ \\
\hline & $\mathrm{HV}=\mathrm{k}_{23} \mathrm{Co}^{0.25}$ & $\mathrm{k}_{23}=40 \mathrm{kgmm}^{-2}(\mathrm{wt} . \% \mathrm{Fe})^{-0.25}$ & $r_{23}=0.997$ \\
\hline & $\sigma=\mathrm{k}_{24} \mathrm{Co}^{0.09}$ & $\mathrm{k}_{24}=169 \mathrm{MPa}(\text { wt. } \% \mathrm{Fe})^{-0.09}$ & $\mathrm{r}_{24}=0.971$ \\
\hline
\end{tabular}

were decreased. Variations in rod spacings with Fe content at a constant $G$ and various $V$ are given in Fig. 7b. The variation of $\lambda$ versus $C_{o}$ is essentially linear on the logarithmic scale. As can be seen from Fig. 7, the data form straight lines, the linear regression analysis gives the proportionality equation for constant $G$ and various V. The relationships between the rod spacings and Fe content were determined by using linear regression analysis. A linear regression analysis gives the proportionality equation as $\lambda=\mathrm{k}_{o}{ }^{-\mathrm{b}}$. The exponent values of $C_{o}$ for $\lambda$ were found to be $-0.43,-0.35,-0.17$ and -0.37 for each growth velocities, respectively (see Table 1$)$. The exponent values of the $V(0.33-0.39)$ are in good agreement with the values of $0.42,0,46,0.42,0.450 .44,0.46$ reported by Wilde et al. ${ }^{19}$ for Al-Cu-Ag eutectic, Gündüz et al. ${ }^{20}$ for Al-Si eutectic, Steinbach and Ratke ${ }^{21}$ for Al-Si-Mg, Aker et al. ${ }^{22}$ for Al-Sb eutectic, Fan et al. ${ }^{23}$ for Al-Si-Ti and Çadırlı et $\mathrm{al}^{24}$ for $\mathrm{Al}-\mathrm{Cu}-\mathrm{Co}$ eutectic, respectively. But, exponent values of $V$ in this work are slightly lower than the value of 0.50 predicted on the basis of the Jackson-Hunt ${ }^{25}$ binary eutectic theory. Until now, there have not any accepted theoretical model for ternary alloys in the literature for compared with experimental results.

\subsection{Effect of growth velocity and Fe content on the microhardness}

The dependencies of microhardness on the growth velocity, eutectic spacing and composition are given in Fig. 8, and the relationships between these parameters are given in Table 1. As seen in Fig. 8, At a constant temperature gradient $(6.7 \mathrm{~K} / \mathrm{mm})$, an increase of the growth velocity resulted in increased microhardness (Fig. 8a). When the growth velocity was increased from 8.3 to $978 \mathrm{~mm} / \mathrm{s}$, microhardness values increased approximately $21 \%, 23 \%$ and $29 \%$ for Al-1.9Mn$\mathrm{xFe}(\mathrm{x}=0.5,1.5$ and 5$)$ alloys respectively

Some of the studies relating to investigation between composition and microhardness have been found in the literature for different alloys, but very few researchers have reported that there is a directly relationship between composition and microhardness. Figure $8 \mathrm{~b}$ shows the variation of $H V$ as a function of $C_{o}$ for various growth velocities. The HV values of alloys increased with increasing Fe content and the highest $\mathrm{HV}$ values were obtained for the Al-1.9Mn-5Fe alloy. With the increase in Fe content, microhardness value increased approximately $70 \%$. As can be seen from Table 1 , the exponent values of the composition are found to be 

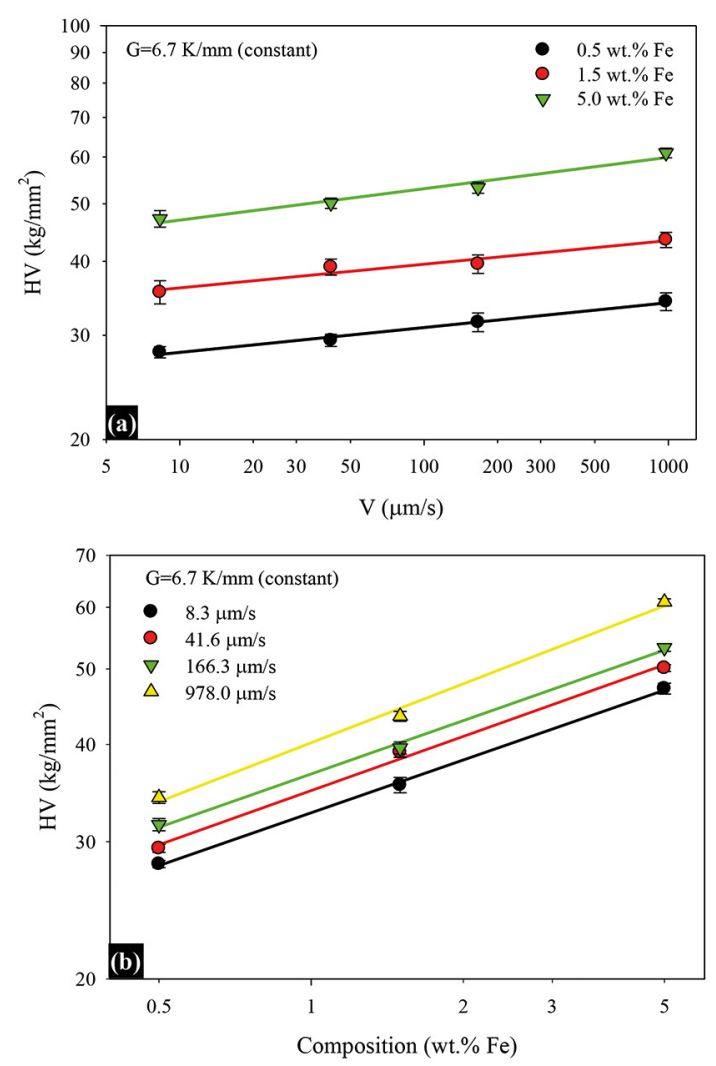

Fig. 8. (a)Variation of $H V$ versus $V$ for different Fe contents (b) Variation of $H V$ versus $C_{o}$ for different $V$

$0.23,0.23,0.24$ and 0.25 for $8.3,41.6,166.3$ and $978 \mu \mathrm{m} / \mathrm{s}$ growth velocities, respectively. This average exponent value (0.24) has been compared with the exponent values obtained in previous works $\mathrm{s}^{26-30}$ for the various alloy systems. The exponent values of $C_{o}$ in this work are close to the values of $0.24,0.28$ and 0.28 obtained by Shah et al. ${ }^{26}$, Wang et al. ${ }^{27}$ and Çadırlı and Kaya ${ }^{28}$ for various alloys, respectively. But, exponent values of composition in this study are smaller than the values of 0.35 and 0.50 obtained by Novinrooz et al..$^{29}$ and Maruyama et al. ${ }^{30}$, respectively. Differences exist in the exponent values because of the possible differences in purity, different alloy compositions, solidification conditions and the surface preparation of the test pieces.

\subsection{Effect of growth velocity and Fe content on the tensile properties}

Another purpose of present work was to study the dependency of tensile strength on $\mathrm{Fe}$ content $(0.5,1.5$ and $5 \mathrm{wt} . \%$ ) and growth velocity in the range of $8.3-978 \mu \mathrm{m} / \mathrm{s}$. For this purpose a series of experiments were made. Typical strength-strain curves of $\mathrm{Al}-1.9 \mathrm{Mn}-\mathrm{xFe}(\mathrm{x}=0.5,1.5$ and 5) alloys are shown in Fig. 9 for different $V$ at a constant $G$ for strain rate $\left(10^{-3} \mathrm{~s}^{-1}\right)$. As can be seen from Fig.9(a-c), while the increasing $V$ and $\mathrm{Fe}$ content, the values of tensile strength
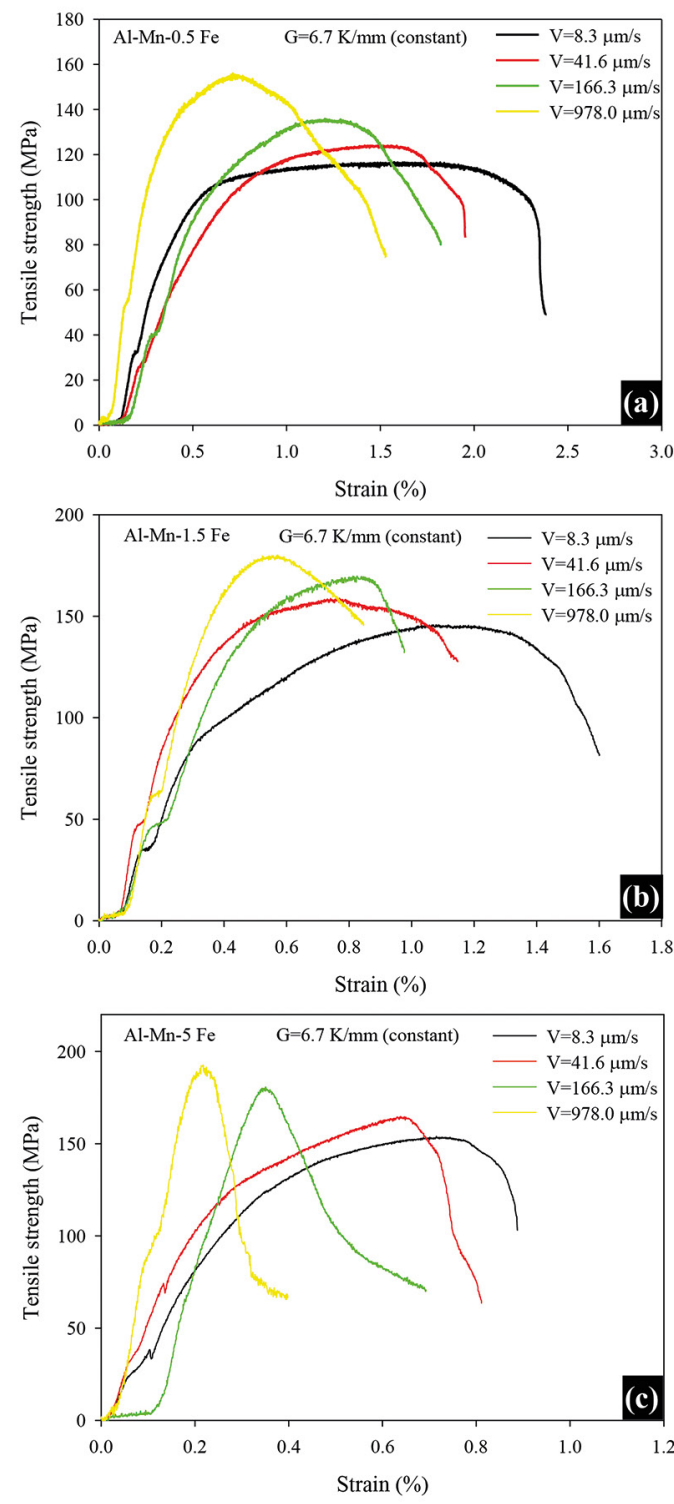

Fig. 9 Typical tensile strength-strain curves of $\mathrm{Al}-1.9 \mathrm{Mn}-\mathrm{xFe}$ alloys for different $V$ at a constant $\mathrm{G}$ (a) $\mathrm{Al}-1.9 \mathrm{Mn}-0.5 \mathrm{Fe}$ (b) $\mathrm{Al}-1.9 \mathrm{Mn}-1.5 \mathrm{Fe}$ (c) $\mathrm{Al}-1.9 \mathrm{Mn}-5 \mathrm{Fe}$

increased, but the values of percent elongation $(\varepsilon)$ decreased. Goulart et al. ${ }^{31}$ carried out directional solidification experiments with hypoeutectic Al-Fe alloys, and reported that with the increase in the alloy Fe content higher density of eutectic fibers was observed, which improved the tensile strength but reduced the ductility. This result is good agreement with our results. In addition, Mukai et al. ${ }^{32}$ were observed similar behavior due to increased Fe content for Al-Fe binary alloys. In this study, Al-Mn-Fe alloy containing $5 \mathrm{wt} . \% \mathrm{Fe}$ shows a higher tensile strength and more brittle feature than the other Al-Mn-Fe alloys. As shown from Fig.10a and Table 1 that an increase in the growth velocity $(V)$ leads to an increase in the ultimate tensile strength $\left(\sigma_{u}\right)$ for each composition. 

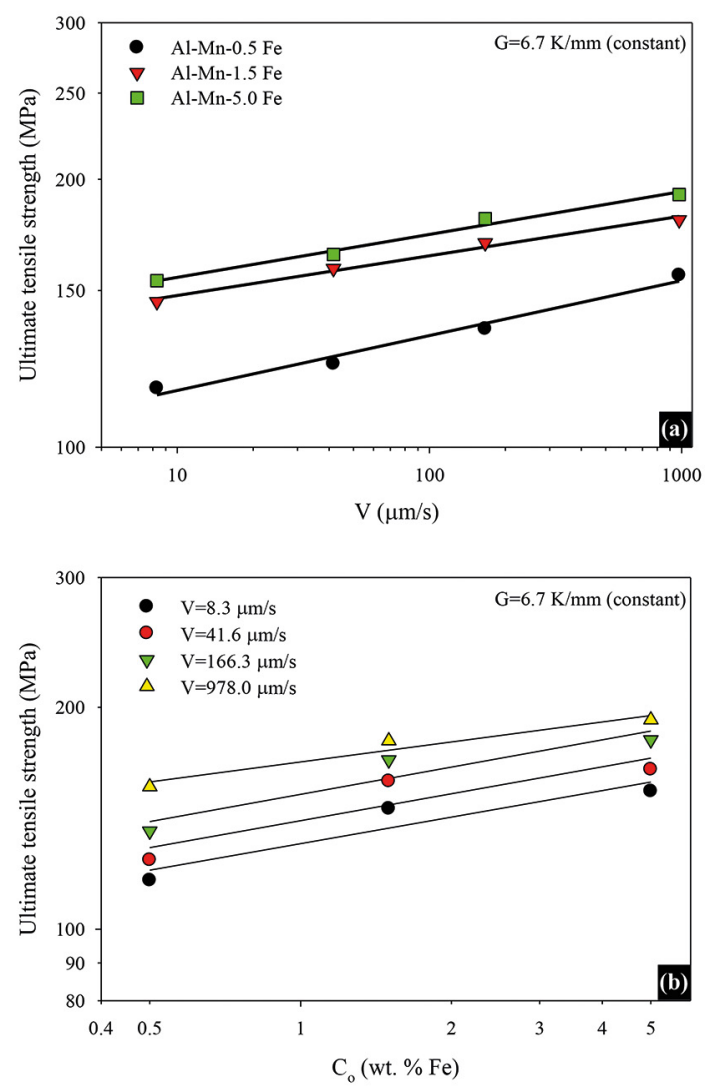

Fig. 10. (a) Variation of the ultimate tensile strength with the $V$ for different $C_{o}$ (b) Variation of the ultimate tensile strength with the $C_{o}$ for different $V$

The values of $\sigma_{u}$ increase with increasing growth velocity (Fig. 10a and Table 1). It was found that increasing the $V$ values from $8.3 \mathrm{~mm} / \mathrm{s}$ to $978 \mathrm{~mm} / \mathrm{s}$, the maximum tensile strength values increase from 116, 146 and154 MPa to 156,180 and192 MPa for each composition $(0.5,1.5$, and 5 Fe wt.\%), respectively. Highest $\sigma_{u}$ values were obtained for the Al-1.9 Mn-5Fe alloy. The increasing $V$ values, $\sigma_{u}$ values increased approximately $34 \%, 24 \%$ and $25 \%$ for each composition $(0.5,1.5$, and $5 \mathrm{Fe}$ wt.\%), respectively.

The exponent value of $V$ was found to be $0.06,0.04$ and 0.05 for $\mathrm{Al}-1.9 \mathrm{Mn}-\mathrm{xFe}(\mathrm{x}=0.5,1.5$ and 5$)$ alloys, respectively (Table 1). The exponent values of $V(0.04-0.06)$ obtained in this study are in good agreement with the values of 0,05 , $0.08,0.09,0.04$ and 0.07 reported by Çadırlı et al. ${ }^{24}$ for $\mathrm{Al}-\mathrm{Cu}-\mathrm{Co}$ eutectic, Aker et al. ${ }^{22}$ for Al-Sb eutectic, Kaya et al. ${ }^{33}$ for Al-Si eutectic, Guo et al. ${ }^{34}$ for NiAl-28Cr-5Mo-1Hf (at\%), Lapin and Marecek ${ }^{35}$ for Ni-21.9Al-8.1Cr-4.2Ta$0.9 \mathrm{Mo}-0.3 \mathrm{Zr}$ (at\%), respectively. But, this exponent value is lower than the values of $0.14,0.15$ and 0.16 reported by Lapin et al. ${ }^{36}$ for Ti-46Al-2W-0.5Si (at\%), Fan et al. ${ }^{37}$ for Ti-46Al-0.5W-0.5Si (at\%) and Fan et al. ${ }^{38}$ for Ti-49 at $\% \mathrm{Al}$ alloy, respectively.

Figure 10b shows the values of $\sigma_{u}$ as a function of $C_{o}$. Highest $\sigma_{u}$ value were obtained for the Al-1.9Mn-5Fe alloy. The $\sigma_{t}$ value increased from $156 \mathrm{MPa}$ to $192 \mathrm{MPa}\left(\sigma_{u}\right.$ values increased approximately $23 \%$ ). As evident from the equations on Table 1, the exponent value of $C_{o}$ is equal to 0.12 (average value).

\subsection{Fracture behavior}

Fracture surface images of the studied alloys were analyzed depending on growth velocity and composition (Fe content) to verify mechanical tests. Figure 11 shows the macroscopic and high magnified appearance of fracture surfaces of the $\mathrm{Al}-1.9 \mathrm{Mn}-\mathrm{xFe}$ alloys for lowest growth velocity $(8.3 \mathrm{~mm} / \mathrm{s})$. These fracture surfaces exhibited a lot of dimples, a characteristic of ductile fracture (Fig. 11b). However, the cleavage fracture feature become more obvious when the $\mathrm{Fe}$ content increases from 0.5 wt.\% to 5 wt.\%. As evident from Fig. 11f, there are some cleavage planes and voids marked with white arrows. Many micro-cracks (white arrows) start from these voids. As can be seen these fractographs, increasing Fe content, the values of percent elongation decreased. Figure 12 shows the macroscopic and high magnified appearance of fracture surfaces of the Al-1.9Mn-xFe alloys for highest growth velocity $(978 \mu \mathrm{m} / \mathrm{s})$. In general, the studied alloys show a clearly macroscopic brittle fracture nature. In particular, in the $\mathrm{Al}-1.9 \mathrm{Mn}-1.5 \mathrm{Fe}$ and $\mathrm{Al}-1.9 \mathrm{Mn}-5 \mathrm{Fe}$ alloys, the mode of fracture significantly changed from less brittle to more brittle. The formation of intermetallic phases $\left(\mathrm{Al}_{6} \mathrm{FeMn}\right)$ at the eutectic cells may provide appropriate sites for crack propagation due to its brittle nature. An important factor that causes brittle fracture is grain size. As grains get smaller in a material, the fracture becomes more brittle. As can be seen from Fig. 12 (c and d), cavity is visible. As the Fe content reaches to 5 wt.\% at highest growth velocity $(978 \mu \mathrm{m} / \mathrm{s})$ (Fig.12e and f), fracture morphologies show intergranular texture including cleavage planes (white arrows). It can be clearly seen that the long rod shape Fe-rich intermetallics interwoven in the $\alpha$-Al matrix. These factors have significantly reduced the amount of elongation.

Hafiz and Kobayashi ${ }^{39}$ conducted a study on the microstructure- fracture behavior relations in $\mathrm{Al}-\mathrm{Si}$ casting alloys using tensile testing. In general, the voids were found to initiate at silicon particles. The individual voids then grew and coalesced, creating micro-cracks in the eutectic region. These microcracks linked up to form the main crack, resulting in the final fracture. Horng et al ${ }^{40}$ studied the fracture behavior of A356 alloys with different iron contents. According to them, the cracks were found to initiate and grow along the eutectic $\mathrm{Si}$ and Fe-rich intermetallic phase particles.

Consequently, the microhardness and tensile strength of the alloys increase with increasing growth velocity and Fe content. Especially, the $\mathrm{Al}-1.9 \mathrm{Mn}-5 \mathrm{Fe}$ alloy would be expected to have the highest microhardness and tensile strength. Because, average spacings between $\mathrm{Al}_{6} \mathrm{FeMn}$ 

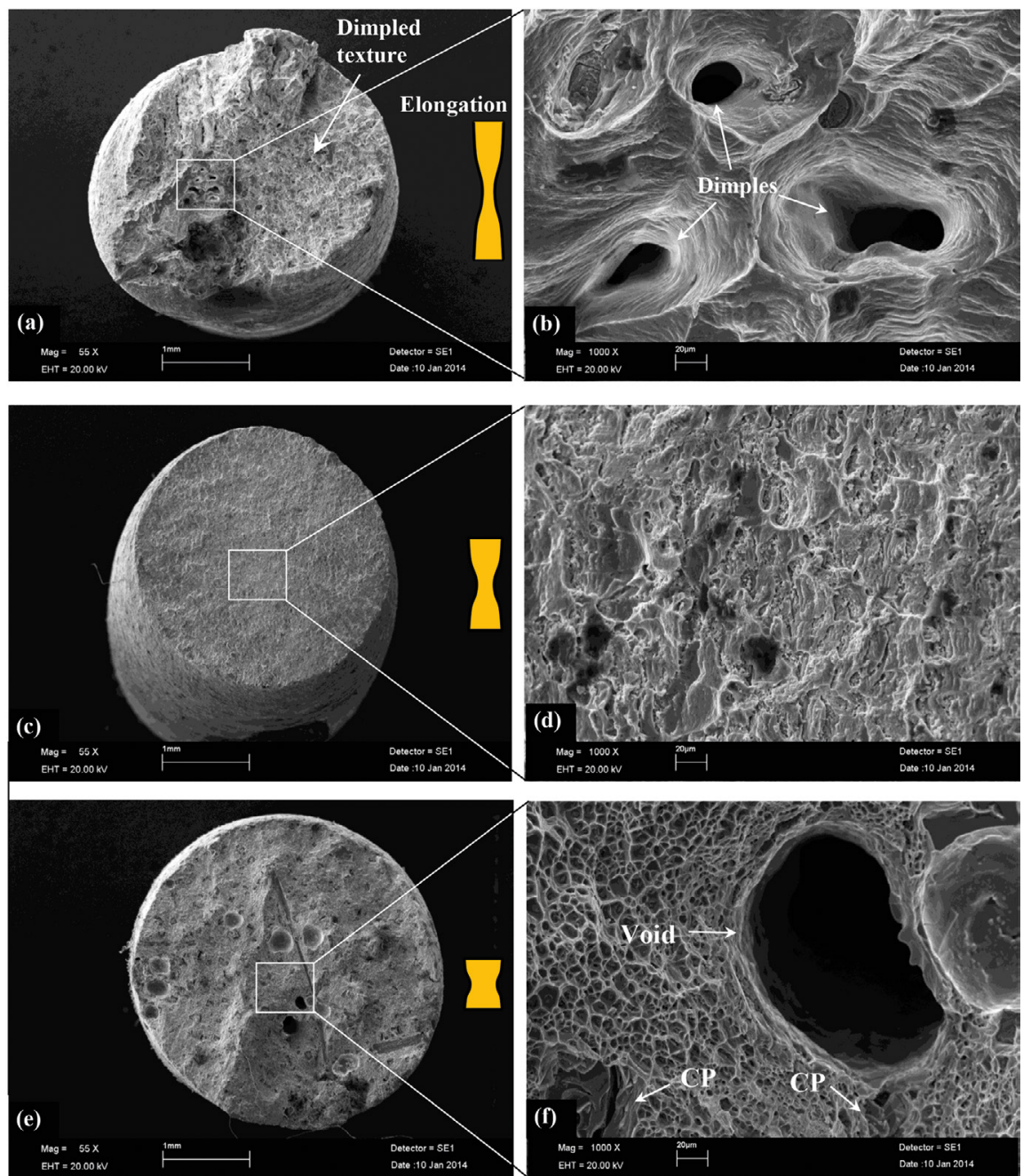

Fig. 11 SEM fractographs showing tensile fracture surface of $\mathrm{Al}-1.9 \mathrm{Mn}-\mathrm{xFe}$ alloys for lowest growth velocity $(V=8.3 \mu \mathrm{m} / \mathrm{s})(\mathrm{a}, \mathrm{b}) \mathrm{Al}-1.9 \mathrm{Mn}-0.5 \mathrm{Fe}$ (c, d) Al-1.9Mn-1.5Fe (e, f) Al-1.9Mn-5Fe (CP: cleavage planes)

intermetallics were decreased and hard $\mathrm{Al}_{6} \mathrm{FeMn}$ rods well refined. Therefore, homogeneous distribution of $\mathrm{Al}_{6} \mathrm{FeMn}$ rods throughout the matrix ( $\alpha$-Al) formed along the interdendritic region that improves the microhardness and tensile strength of the matrix.

\section{Conclusions}

Influence of composition on the microstructure, mechanical and electrical properties of $\mathrm{Al}-26 \mathrm{Cu}-0.5 \mathrm{Fe}-\mathrm{xSi}$ alloys has investigated in this research. The results are summarized as follows:

1. Eutectic spacings $(\lambda)$ of $\mathrm{Al}-1.9 \mathrm{Mn}-\mathrm{xFe}$ alloys decrease with increasing growth velocity and $\mathrm{Fe}$ content. The relationships between the $\lambda, V$ and $C_{o}$ were obtained by binary regression analysis as follows, $\lambda=k V^{-a}(\mathrm{a}=0.39,0.33$ and a.34), $\lambda=k \mathrm{C}_{\mathrm{O}}{ }^{-\mathrm{b}}(\mathrm{b}=0.43,0.35,0.17$ and 0.37$)$,
2. The experimental results show that $H V$ values of studied alloys increase with increasing $V$ and $\mathrm{Fe}$ content. The establishment of the relationship between $H V, V$ and $C_{o}$ can be given as $H V=k V^{c}(\mathrm{c}=0.4,0.4$ and 0.5$), H V=k C^{d}{ }_{O}(\mathrm{~d}=0.23,0.23,0.24$ and 0.25$)$

3. Also, by increasing $V$ and Fe content, $\sigma_{u}$ increase and elongation decreases. It is found that $\sigma_{u}$ increases from 116, 146 and $154 \mathrm{MPa}$ to 156,180 and 192 $\mathrm{MPa}$ for each alloy composition, respectively. The establishment of the relationships among $\sigma$, $\mathrm{V}$ and $\mathrm{C}_{\mathrm{o}}$ can be given as $\sigma_{u}=k V^{e}(\mathrm{e}=0.6,0.4$ and 0.5$)$, $\sigma_{u}=k C_{o}^{f}(\mathrm{f}=0.12,0.12,0.12$ and 0.09$)$.

4. As the $\mathrm{V}$ and Fe content increases, the fracture surfaces show more brittle features. Especially, the number density of $\mathrm{Fe}$-containing intermetallics ( $\left.\mathrm{Al}_{6} \mathrm{FeMn}\right)$ increases with Fe content, and therefore since these participate directly in the fracture mechanism, the more intermetallics there are, the 

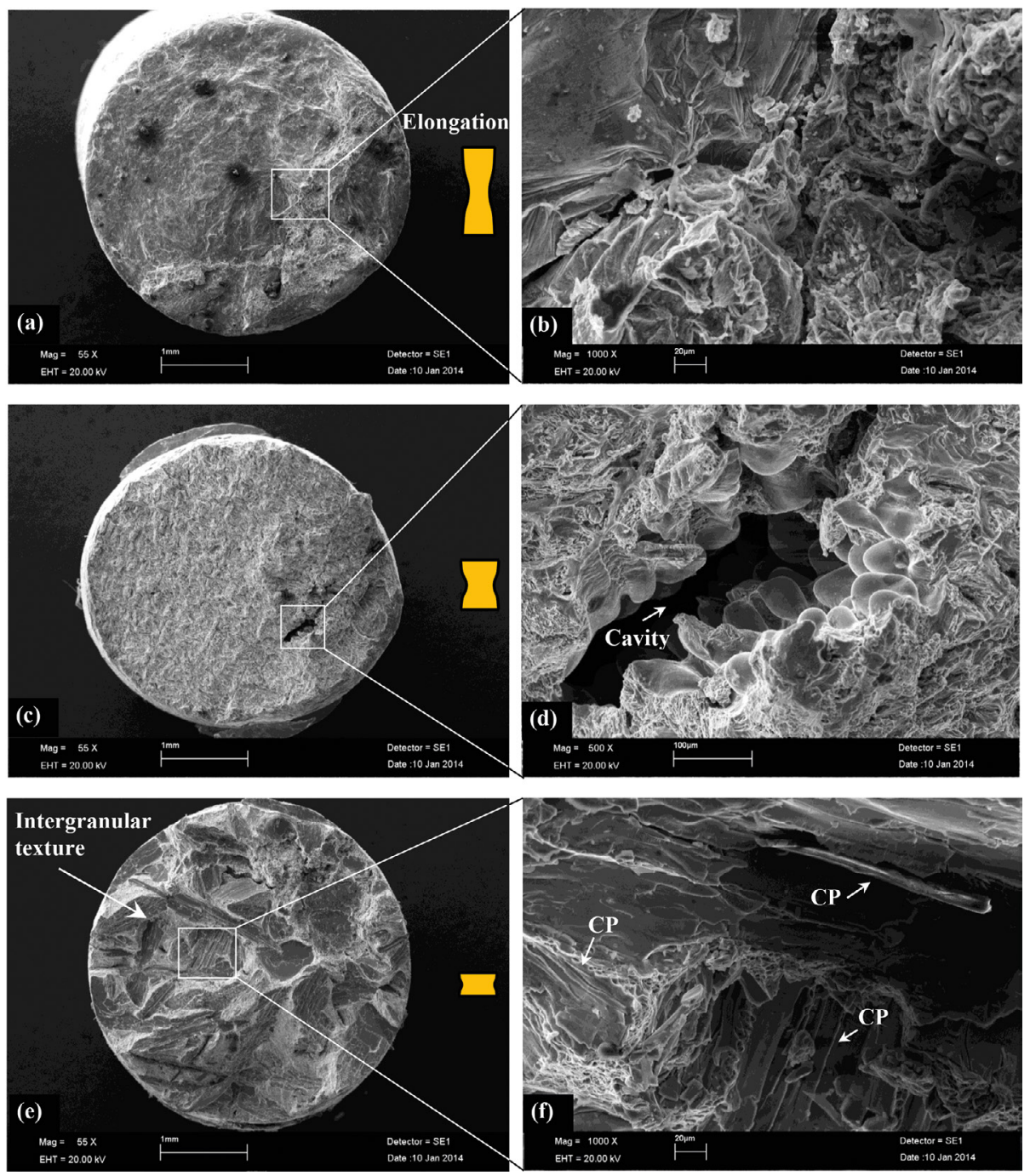

Fig. 12 SEM fractographs showing tensile fracture surface of A1-1.9Mn-xFe alloys for biggest growth velocity $(V=978 \mu \mathrm{m} / \mathrm{s})(\mathrm{a}, \mathrm{b}) \mathrm{Al}-1.9 \mathrm{Mn}-0.5 \mathrm{Fe}(\mathrm{c}, \mathrm{d}) \mathrm{Al}-1.9 \mathrm{Mn}-1.5 \mathrm{Fe}(\mathrm{e}, \mathrm{f}) \mathrm{Al}-1.9 \mathrm{Mn}-5 \mathrm{Fe}$

lower the ductility. Thus, as iron level increases, porosity increases, and this defect also has an impact on ductility.

5. As can be seen from exponent values in the obtained experimental relationships, the effect of $\mathrm{V}$ and $\mathrm{Fe}$ content at a constant $\mathrm{G}$ is quite effective. Thus, $\mathrm{V}$ and Fe content play a vital role for a good combination of microstructure and mechanical properties.

\section{Acknowledgements}

This research was supported financially by the Scientific and Technical Research Council of Turkey (TUBITAK) under contract no. 212T130. The authors are grateful to the Scientific and Technical Research Council of Turkey (TUBITAK) for their financial supports.

\section{References}

1. Mondolfo LF. Manganese in aluminum alloys. Paris: The Manganese Centre; 1978.

2. Avner SH. Introduction to Physical Metallurgy. New York: McGraw-Hill; 1974. p. 481-489.

3. Polmear IJ. Light Alloys: Metallurgy of the Light Metals. Hoboken: Wiley; 1995.

4. Cahn RW, Haasen P, Kramer EJ, eds. Materials Science and Technology: A Comprehensive Treatment. Weinheim: WileyVCH; 1996. p. 242-244, 267-273.

5. Craig BD, Anderson BD, eds. Handbook of Corrosion Data. Materials Park: ASM International; 1995.

6. Denholm WT, Esdaile JD, Siviour NG, Wilson BW. The nature of the $\mathrm{FeAl}_{3}$ liquid-(FeMn)Al reaction in the Al-Fe-Mn system. Metallurgical and Materials Transactions A. 1987;18(3):393-397.

7. Shabestari SG. The effect Fe and Mn on formation of intermetallic compounds in Al-Si alloys. Materials Science and Engineering A. 2004;383:289. 
8. Hwang JY, Doty HW, Kaufman MJ. The effects of Mn additions on the microstructure and mechanical properties of $\mathrm{Al}-\mathrm{Si}-$ $\mathrm{Cu}$ casting alloys. Materials Science and Engineering $A$. 2008;488(1-2):496-504.

9. Dinnis CM, Taylor JA, Dahle AK. Interactions between iron, manganese, and the Al-Si eutectic in hypoeutectic Al-Si alloys. Metallurgical and Materials Transactions A . 2006;37(11):32833291.

10. Dutta B, Rettenmayr M. Effect of cooling rate on the solidification behaviour of Al-Fe-Si alloys. Materials Science and Engineering A. 2000;283(1-2):218-224.

11. Zhang YH, Liu YC, Han YJ, Wei C, Gao ZM. The role of cooling rate in the microstructure of Al-Fe-Si alloy with high $\mathrm{Fe}$ and Si contents. Journal of Alloys and Compounds. 2009;473(12):442-445.

12. Çadırlı E. Effect of solidification parameters on mechanical properties of directionally solidified Al-rich Al-Cu alloys. Metals and Materials International. 2013;19(3):411-422.

13. Yılmaz E, Çadırlı E, Acer E, Gündüz M. Microstructural Evolution and Mechanical Properties In Directionally Solidified Sn-10.2 Sb Peritectic Alloy at a Constant Temperature Gradient. Materials Research. 2016;19(2):370-378.

14. Davis JR, ed. ASM Specialty Handbook: Aluminum and Aluminum Alloys. Materials Park: ASM International; 1993.

15. Ourdjini A, Liu J, Elliott R. Eutectic spacing selection in the Al-Cu system. Materials Science and Technology. 1994;10(4):312-318.

16. Ganesan S, Chan CL, Poirier DR. Permeability for flow parallel to primary dendrite arms. Materials Science and Engineering A. 1992;151(1):97-105.

17. Bhat MS, Poirier DR, Heinrich JC. Permeability for cross flow through columnar-dendritic alloys. Metallurgical and Materials Transactions B. 1995;26(5):1049-1056.

18. Kaya H, Çadırlı E, Böyük U, Maraşılı N. Variation of microindentation hardness with solidification and microstructure parameters in the Al based alloys. Applied Surface Science. 2008;255(5 Pt 2):3071-3078.

19. De Wilde J, Froyen L, Rex S. Coupled two-phase $\left[\operatorname{alpha}(\mathrm{Al})+\operatorname{theta}\left(\mathrm{Al}_{2} \mathrm{Cu}\right)\right]$ planar growth and destabilisation along the univariant eutectic reaction in $\mathrm{Al}-\mathrm{Cu}-\mathrm{Ag}$ alloys. Scripta Materialia. 2004;51(6):533-538.

20. Gündüz M, Kaya H, Çadırlı E, Özmen A. Interflake spacings and undercoolings in Al-Si irregular eutectic alloy. Materials Science and Engineering: A. 2004;369(1-2):215-229.

21. Steinbach S, Ratke L. The influence of fluid flow on the microstructure of directionally solidified AlSi-base alloys. Metallurgical and Materials Transactions A. 2007;38:1388-1394.

22. Aker A, Engin S, Y1lmazer I, Kaya H. Influence of the growth rate on physical properties in the aluminum-antimony eutectic alloy. International Journal of Materials Engineering and Technology. 2013;9(1):59-76.

23. Fan J, Li X, Su Y, Guo J, Fu H. The microstructure parameters and microhardness of directionally solidified $\mathrm{Ti}-43 \mathrm{Al}-3 \mathrm{Si}$ alloy. Journal of Alloys and Compounds. 2010;506(2):593-599.
24. Çadırlı E, Yılmazer İ, Şahin M, Kaya H. Investigation of the Some Physical Properties of the Directionally Solidified Al-Cu-Co Ternary Eutectic Alloy. Transactions of the Indian Institute of Metals. 2015;68(5):817-827.

25. Jackson KA, Hunt JD. Lamellar and rod eutectic growth. Transactions of the Metallurgical Society of AIME. 1966;236:1129-1142.

26. Shah KV, Goswami M, Deo MN, Sarkar A, Manikandan S, Shrikhande VK, et al. Effect of $\mathrm{B}_{2} \mathrm{O}_{3}$ addition on microhardness and structural features of $40 \mathrm{Na}_{2} \mathrm{O}-10 \mathrm{BaO}-\mathrm{xB}_{2} \mathrm{O}_{3}-\left(50-\mathrm{x}_{2} \mathrm{P}_{2} \mathrm{O}_{5}\right.$ glass system. Bulletin of Materials Science. 2006;29(1):43-48.

27. Wang X, Lu HM, Li XL, Li L, Zheng YF. Effect of cooling rate and composition on microstructures and properties of $\mathrm{Zn}-\mathrm{Mg}$ alloys. Transactions of Nonferrous Metals Society of China. 2007; 17:122-125.

28. Cadırlı E, Kaya H. The effect of composition on microhardness and determination of electrical and thermal properties in the Sn-Cu alloys. Journal of Materials Science: Materials in Electronics. 2011;22(9):1378-1386.

29. Novinrooz AJ, Seyedi H, Larijani MM. Microhardness study of Ti(C, N) films deposited on S-316 by the Hallow Cathode Discharge Gun. Journal of Achievements in Materials and Manufacturing Engineering. 2006;14(1-2):59-63.

30. Maruyama K, Suto K, Nishizawa J. Compositional Dependence of Hardness in $\mathrm{ZnSe}_{1-\mathrm{x}} \mathrm{Te}_{\mathrm{x}}$ and $\mathrm{Be}_{\mathrm{y}} \mathrm{Zn}_{1-\mathrm{y}} \mathrm{Se}_{1-\mathrm{x}} \mathrm{Te}_{\mathrm{x}}$. Japanese Journal of Applied Physics. 2000;39(Pt $19 \mathrm{~A}): 5180-5183$.

31. Goulart PR, Cruz KAS, Spinelli JE, Cheung N, Ferreira I, Garcia A. Cellular growth during transient directional solidification of hypoeutectic Al-Fe alloys. Journal of Alloys and Compounds. 2009;470(1-2):589-599.

32. Mukai T, Suresh S, Kita K, Sasaki H, Kobayashi N, Higashi $\mathrm{K}$, Inoue A. Nanostructured Al-Fe alloys produced by e-beam deposition: static and dynamic tensile properties. Acta Materialia. 2003;51(14):4197-4208.

33. Kaya H, Çadırlı E, Gündüz M, Ülgen A. Effect of the temperature gradient, growth rate, and the interflake spacing on the microhardness in the directionally solidified Al-Si eutectic alloy. Journal of Materials Engineering and Performance. 2003;12(5):544-551.

34. Guo JT, Xu CM, Du XH, Fu HZ. The effect of solidification rate on microstructure and mechanical properties of an eutectic NiAlCr(Mo)-Hf alloy. Materials Letters. 2004;58(26):3233-3236.

35. Lapin J, Marecek J. Effect of growth rate on microstructure and mechanical properties of directionally solidified multiphase intermetallic $\mathrm{Ni}-\mathrm{Al}-\mathrm{Cr}-\mathrm{Ta}-\mathrm{Mo}-\mathrm{Zr}$ alloy. Intermetallics. 2006;14(10-11):1339-1344.

36. Lapin J, Ondrúš L, Nazmy M. Directional solidification of intermetallic $\mathrm{Ti}-46 \mathrm{Al}-2 \mathrm{~W}-0.5 \mathrm{Si}$ alloy in alumina moulds. Intermetallics. 2002;10(10):1019-1031.

37. Fan J, Li X, Su Y, Guo J, Fu H. Dependency of microhardness on solidification processing parameters and microstructure characteristics in the directionally solidified Ti-46Al- $0.5 \mathrm{~W}-0.5 \mathrm{Si}$ alloy. Journal of Alloys and Compounds. 2010;504(1):60-64. 
38. Fan J, Li X, Su Y, Chen R, Gou J, Fu H. Dependency of microstructure parameters and microhardness on the temperature gradient for directionally solidified Ti-49Al alloy. Materials Chemistry and Physics. 2011;130(3):1232-1238.

39. Hafiz MF, Kobayashi T. A study on the microstructure-fracture behavior relations in Al-Si casting alloys. Scripta Metallurgica et Materialia. 1994;30(4):475-480.
40.Horng JH, Jiang DS, Lui TS, Chen LH. The fracture behaviour of A356 alloys with different iron contents under resonant vibration. International Journal of Cast Metals Research. 2000;13(4):215-222. 